\title{
Healthy beverage consumption among aging Thai consumers
}

\section{Watcharapoj Sapsanguanboon * ${ }^{*}$, Runchida Daoruang **}

* Graduate School of Management and Innovation,

King Mongkut's University of Technology Thonburi, Thailand

** Rajabhat Kanchanaburi University, Thailand

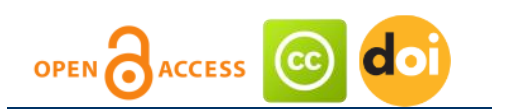

Article history:

Received: May 11, 2019

1st Revision: September

30, 2019

Accepted: November 18, 2019

\section{JEL classification: \\ D11 \\ D18 \\ H75}

DOI:

10.14254/jems.2019.4-2.4

\begin{abstract}
This study analyzes the trends of healthy beverage consumption of aging consumers in central Thailand. It examines the relationship between demography and beverage consumption behavior of aging consumers. A questionnaire survey is used to collect information on healthy beverage consumption behavior and consumers' demography. An in-depth interview is employed to explore the general preferences related to healthy beverage consumption of aging consumers in central Thailand. The results show that aging consumers in central Thailand are health conscious. They pay more attention to food and beverage consumption, which has both functional and emotional benefits. As such, the demand for healthy beverage consumption increases with age. Fruit or vegetable juice is the best choice for them. However, their dietary requirements depend on individual, social, and environmental factors in addition to age. Particularly, their income sources and living conditions are important, because they have a direct effect on healthy beverage consumption.
\end{abstract}

Keywords: aging consumers, healthy beverage, emerging segment.

\section{Introduction}

According to a survey of the global aging population conducted by the United Nations (2017), the population aged 60 years over was 929 million in 2017, which was more than twice that in 1980. The survey also predicted that the aging population will double by 2050. In 2016, Thailand's population reached 65.9 million. The elderly, who were 10.3 million in number, comprised $16 \%$ of total population (Office of the National Economic and Social development board, 2013). The aging population and the health problems of the elderly have an economic and social effect on a country given the low performance. (National Statistical Office, 2015). In a survey about the health conditions of the elderly in Thailand conducted by Thai Gerontology Research and Development Institute (2016), 53.2\% of the respondents were diagnosed with hypertension, 18.1\%

Corresponding author: Watcharapoj Sapsanguanboon

E-mail: watcharapoj.sap@kmutt.ac.th

This open access article is distributed under a Creative Commons Attribution (CC-BY) 4.0 license. 
with diabetes, $35.4 \%$ with obesity, $49.4 \%$ with abdominal obesity, and $46.8 \%$ with metabolic syndrome. The survey also found that aging was related to lower fruit consumption, especially for those aged 70 years and above. Furthermore, given that more than half the elderly population has less than 20 teeth, it is difficult for them to chew food. Accordingly, consuming healthy beverages is a way to meet their daily nutritional requirements. Further, these beverages are easy to ingest and digest. This research analyzes the trends of healthy beverage consumption for aging consumers in central Thailand. It examines the relationship between demography and beverage consumption behaviors of aging consumers. The findings should help food and beverage producers to develop the right products to serve an emerging market segment.

\section{Aging consumers}

Aging does not have a uniform definition and is a subjective concept, as there is no specific age at which the process of aging begins, However, it can be defined as a phase in one's life cycle. Rose (1991) defined is as, "[a] persistent decline in the age-specific fitness components of an organism due to internal physiological deterioration."

In Britain, the Friendly Societies Act (1875) defined old age as "any age after 50." However, the age eligibility criterion for pension schemes is generally 60 to 65 years (Roebuck, 1979). Furthermore, most developed countries consider 65 years as the benchmark. However, the United Nations has not adopted a standard criterion. It generally uses a benchmark of 60 years (personal correspondence, 2001), as indicated in its latest report on "World population aging 2017."

\section{Consumer behavior theory}

Consumer behavior research allows us to understand consumption trends. It is the study of how individuals, groups, and organizations select, buy, use, and dispose of goods, services, ideas, or experiences, to satisfy their needs and wants. According to Kotler and Keller (2012), consumer behavior is influenced by cultural, social, and personal factors. Of these, social factors exert the greatest influence.

Cultural factors are particularly important determinants of a person's wants and behavior and encompass family background and exposure to key institutions. Social factors relate to daily life. Personal factors are personal characteristics that influence a customer's decision, including age, stage in the family life cycle, personality, self-concept, and lifestyle.

This theory sets the scope of the research questions and will enable us to efficiently analyze consumer behavior trends.

\section{Aging consumer behavior}

The aging global population presents businesses with a challenge to create products and services that serve the needs of the elderly. This group has economic as well as health concerns, providing various industries with an opportunity to address its needs with affordable products and services. This is especially true for the food and beverage industry, given its role in meeting nutritional needs, sustaining life, and controlling, preventing, or treating diseases.

Trichopoulou and Vansilopoulou (2000) found that the Mediterranean diet improved health and longevity. Furthermore, according to the HALE (Healthy Aging: Longitudinal Study in Europe) project, the Mediterranean diet lowers cause-specific mortality risk (Boger st al., 2005).

However, despite the proven benefits of following certain diets, the aging population may be reluctant to purchase certain kinds of foods and beverages even if these products are of interest to them, given this group's complex preferences that vary by country or region, age, income, and lifestyle (Cabrini and Ajit, 2006).

Cecília, Cláudia and M.D.V. (2010) conducted an interview survey of the elderly population in Portugal, to examine the effects of their physiology, family life cycle, and types of meal consumed across the week on their food consumption patterns. The results showed that health problems and physiological constraints along with social change, loss of partner, or loneliness were major factors influencing their food choice.

Subhadip Roy and Shamindra Nath Sanyal (2017) explored the dimensions of perceived consumption vulnerability (PCV) for the elderly in India and its usefulness for marketers and policymakers to understand consumption behavior. They found five dimensions that affected the PCV: physical, financial, social, technological, and service vulnerability. Their findings aimed to address the difficulties faced by marketers when targeting the elderly segment and formulating a specific strategy for this group.

Overall, it can be concluded that healthy food is positively associated with longevity among the elderly. However, not all elderly people can consume healthy food, as their food intake depends on other factors.

Healthy beverages for aging consumers

Physiological changes associated with aging involve the slowing down of biological processes and decrease in appetites. Soft food and liquids are easy to chew and digest, and the elderly can consume them to meet their nutritional requirements. 
An NSTDA Conference about food innovation for an aging society (2017) identified nutrients and ingredients in beverages that can provide the elderly with significant benefits including disease prevention and health improvement: high fiber, high protein to build and maintain muscles, whole grain or calcium fortification, and vitamins and minerals. For example, herbal teas, herbal drinks, $100 \%$ juices, cereal drinks, skimmed milk, and function drinks are currently sold on the market for the elderly (Songvit Hongprasert, 2016).

\section{Market for healthy beverages in Thailand}

Current trends of the beverage industry are positive. This is especially true for healthy beverage, because of increasing health consciousness. The healthy beverage market experienced a continuous annual growth rate of 7.2\% between 2011 and 2016. In Thailand, healthy soft drinks (cool drinks) experience higher sales growth than hot drinks, given the country's tropical climate.

The value of the health beverage industry is expected to increase to THB 58 billion in five years, equivalent to a growth rate of 5.3\%. Healthy hot drinks are expected to comprise THB 3 billion and healthy soft drinks, THB 55 billion (National food Institute, 2016).

Overall, it can be concluded that a growing share of health-conscious consumers provides opportunities to health beverage businesses. However, manufactures need to understand the lifestyle and specific needs of the segment they cater to, in order to grow and maximize profitability and efficiency.

\section{Research methodology}

This study combines a qualitative and quantitative approach. Data were collected through descriptive research and attitude measurement as well as in-depth interviews. These methods are common in the study of consumption behavior and can forecast consumption trends (Guntalee Ruenrom, 2016, p. 39-44, 108-136).

First, a descriptive survey collected basic information and lifestyle-related data of consumers aged 60 years and above in Thailand. The questions were adapted from a survey on the situation of the elderly in Thailand in 2015, conducted by the Thailand Gerontology Research and Development Institute (2016). Questions regarding consumption behavior were based on studies examining the determinants of soft drink consumption (2014), its association with behavioral problems in fiveyear-old children (2013), and tea or coffee consumption and lifestyle-related factors (2012).

Second, in-depth interviews were conducted with specific questions based on the results of the survey described above. This was done to humanize the objective information collected, as the topic being discussed is subjective in nature. This step was influenced by a study published in the Journal of Aging Consumption in Portugal (2010), which conducted interviews to collect data.

The two approaches are detailed below.

\section{Sampling}

Descriptive survey

The current study targets residents of central Thailand aged 60 years or above. According to the National Statistical Office (2017), the elderly population in Thailand is 10,014,705 million, and that in central Thailand is 2,563,764 million, comprising is $25.6 \%$ of the total. This study used the Taro Yamane formula (Yamane, 1973) with a 95\% confidence level to compute the sample size. The resulting value was 399.94 , rounded off to 400 rather than 399 to ensure reliability.

\section{In-depth interview}

Six residents of central Thailand aged 60 or above were selected using purposive sampling, and questions were based on the findings of the descriptive survey.

\section{Data collection}

Data were collected from February $1^{\text {st }}$ to April 30th 2019 . Data were obtained from a questionnaire survey of 383 elderly people that knew about health drinks. The data collection procedure presented challenges, as several questions needed to be clarified for the surveyed group, and the period was limited.

The questionnaire items pertained to demographics (gender, age, education, income, source of income, living conditions, and health issues), healthy drink-related behavior (consumption, type of drinks, consumption per week, and average amount consumed). Factors affecting the consumption of healthy drinks were also surveyed with a 5-point Likert scale.

The questionnaire was validated and tested for reliability by 40 participants, who were not included in the final samples. Cronbach's Alpha as used to estimate the reliability of the scale, and yielded a value of 0.813 . above the minimum criterion of 0.70 , indicating reliability.

\section{Data analysis}

Descriptive statistics, including frequency, percentage, mean, and standard deviation, are used for data analysis. Thereafter, inferential statistics are used to compare the means between two and three sets, using an independent-sample t-test and one-way analysis of variance (ANOVA). 
Least squares difference (LSD) is used to identify a trend and test the hypothesis. Finally, the linear correlations between pairs of variables are measured using Pearson's correlation coefficient.

\section{Findings and discussion}

\section{Demographic data}

Demographic data of the 383 respondents show that females comprised a slightly higher percentage than males (54.60\% versus 45.40\%). The age ranges were distributed as follows: 60-69 years (66.10\%), 70-79 years (22.70\%), and above 80 years (11.2\%). Of all respondents, $42.00 \%$ had an undergraduate degree, $37.90 \%$ a bachelor's degree, $19.10 \%$ a master's degree, and $1.00 \%$ a doctorate degree.

Further, 33.90\% respondents earned an income higher than THB40,000, 29.80\% earned lower than THB15,000, and 14.40\% earned incomes ranging from THB20,000 to THB25,000. The income source was work for most respondents (37.60\%), while $23.80 \%$ depended on children for income, $19.80 \%$ on pension, and $11.2 \%$ drew from savings. Totally, $43.10 \%$ of the respondents were living with a child, $33.9 \%$ with a spouse, and $14.10 \%$ with relatives.

Finally, $28.30 \%$ of respondents had less than 20 teeth, $23.80 \%$ had been diagnosed with hypertension, and $15.00 \%$ with osteoarthritis.

Attitude toward drinks and healthy drinks

The survey found that $18.80 \%$ of respondents usually drink coffee, $17.30 \%$ drink fruit or vegetable juice, and $11.80 \%$ have functional drinks. All the respondents had tried healthy drinks before. Most preferred cool drinks (49.30\%) to hot drinks (38.90\%), while $11.70 \%$ preferred drinks served at room temperature. While the frequency of consumption of healthy drinks was less than once a week for $34.70 \%$ of the respondents, $24.80 \%$ consumed healthy drinks every day. Over $10.70 \%$ of respondents consumed healthy drinks once to thrice per week.

Factors that affect the consumption of healthy drinks

Data collected from questionnaire survey were used to compute the average of factors affecting healthy beverage consumption of aging consumers, in order to identify factors that particularly matter to them. The computations are summarized in Table I. The factors can be divided into three groups: individual, social, and environmental determinants.

\begin{tabular}{llcc}
\multicolumn{1}{l}{ Table 1: Factors that affect healthy beverage consumption for aging consumers } & Mean & SD \\
\hline & Subcategory & 3.9190 & 0.44784 \\
Category & & 4.5901 & 0.66443 \\
& Need to feel and be healthy & 3.7441 & 0.87269 \\
& Good taste & 4.3446 & 0.74936 \\
& Awareness of potential healthy impact & 2.9974 & 0.97481 \\
Social determinants determinants & Price & 2.6560 & 0.59857 \\
& & 2.0809 & 0.92449 \\
& Habitual behavior & 2.1932 & 0.97844 \\
& Friend facilitates consumption & 3.1201 & 0.96601 \\
& Family facilitates consumption & 3.2298 & 0.94312 \\
Environment determinants & Doctor's attitude & 2.5313 & 0.59804 \\
& & 3.4308 & 0.98936 \\
& Branding & 2.2872 & 0.97670 \\
& Trends of market & 2.0966 & 0.97270 \\
& Social drinker & 2.3107 & 0.88031 \\
\hline
\end{tabular}

The data in Table 1 show that respondents were mainly interested in individual determinants, with the highest average at 3.9190, followed by social determinants at a moderate level and environment determinants at a low level with an average of 2.6560 and 2.5313 respectively.

In the case of individual determinants, the respondents displayed maximum interest in the need to feel and be healthy, with an average value of 4.5901, followed by other factors namely, the awareness of potential, good taste and price respectively.

As regards social determinants, the respondents were moderately influenced by their doctor's attitude, with a mean of 3.2298, followed by the factors family facilitates consumption, friend facilitates consumption, and habitual behavior.

With respect to environment-related determinants, respondents were influenced mainly by the branding factor, with a high average of 3.4308, followed by taste of relaxation, market trends, and social drinker. Going by the fact that brand addiction is a psychological state that entails an emotional attachment to a particular brand, driven by compulsive urges that generally provide 
pleasure (Mrad, 2018), it is inferred that the elderly usually pay more attention to the brand than market trends and social drinking.

\section{Descriptive survey}

The comparison between the types of drinks and the range of age revealed that the demand for healthy beverage consumption increases with age. Although most respondents prefer coffee, the interest in healthy drinks increases with age. The data from Table 2 is converted into a mean plot. When we study the trend line after forecasting, it is found that there is a higher demand for healthy beverages as compared to other beverages. While fruit or vegetable drinks and Herb drinks have a high average overall, fruit or vegetable drinks are the most popular among all age groups, with a high average (Figure 1,2).

\begin{tabular}{|c|c|c|c|}
\hline Type of beverage & Age (years) & Mean & Std Deviation \\
\hline \multirow{3}{*}{ Tea } & $60-69$ & 0.3083 & 0.46271 \\
\hline & $70-79$ & 0.2184 & 0.41555 \\
\hline & $>80$ & 0.3953 & 0.49471 \\
\hline \multirow[t]{3}{*}{ Milk } & $60-69$ & 0.3202 & 0.46746 \\
\hline & $70-79$ & 0.2874 & 0.45515 \\
\hline & $>80$ & 0.4651 & 0.50468 \\
\hline \multirow[t]{3}{*}{ Coffee } & $60-69$ & 0.6719 & 0.47044 \\
\hline & $70-79$ & 0.6437 & 0.48169 \\
\hline & $>80$ & 0.0233 & 0.15250 \\
\hline \multirow[t]{3}{*}{ Soda } & $60-69$ & 0.1779 & 0.38316 \\
\hline & $70-79$ & 0.0460 & 0.21065 \\
\hline & $>80$ & 0.1163 & 0.32435 \\
\hline \multirow[t]{3}{*}{ Thai sweet drinks } & $60-69$ & 0.0711 & 0.25758 \\
\hline & $70-79$ & 0.1494 & 0.35857 \\
\hline & $>80$ & 0.2326 & 0.42746 \\
\hline \multirow[t]{3}{*}{ Alcohol } & $60-69$ & 0.0791 & 0.27035 \\
\hline & $70-79$ & 0.0115 & 0.10721 \\
\hline & $>80$ & 0.000 & 0.0000 \\
\hline \multirow{3}{*}{ Fruit or vegetable juice } & $60-69$ & 0.4862 & 0.50080 \\
\hline & $70-79$ & 0.6552 & 0.47807 \\
\hline & $>80$ & 0.6744 & 0.47414 \\
\hline \multirow[t]{3}{*}{ Herb drinks } & $60-69$ & 0.3083 & 0.46271 \\
\hline & $70-79$ & 0.3103 & 0.46532 \\
\hline & $>80$ & 0.7674 & 0.42746 \\
\hline \multirow[t]{3}{*}{ Mineral water } & $60-69$ & 0.1304 & 0.33745 \\
\hline & $70-79$ & 0.1379 & 0.34683 \\
\hline & $>80$ & 0.0000 & 0.0000 \\
\hline \multirow[t]{3}{*}{ Functional drinks } & $60-69$ & 0.3557 & 0.47968 \\
\hline & $70-79$ & 0.4368 & 4.9886 \\
\hline & $>80$ & 0.3488 & 0.482224 \\
\hline \multirow[t]{3}{*}{ Others } & $60-69$ & 0.2411 & 0.42860 \\
\hline & $70-79$ & 0.2759 & 0.44954 \\
\hline & $>80$ & 0.1163 & 0.32435 \\
\hline
\end{tabular}

Figure 1: Mean plot between type of drink and range of age

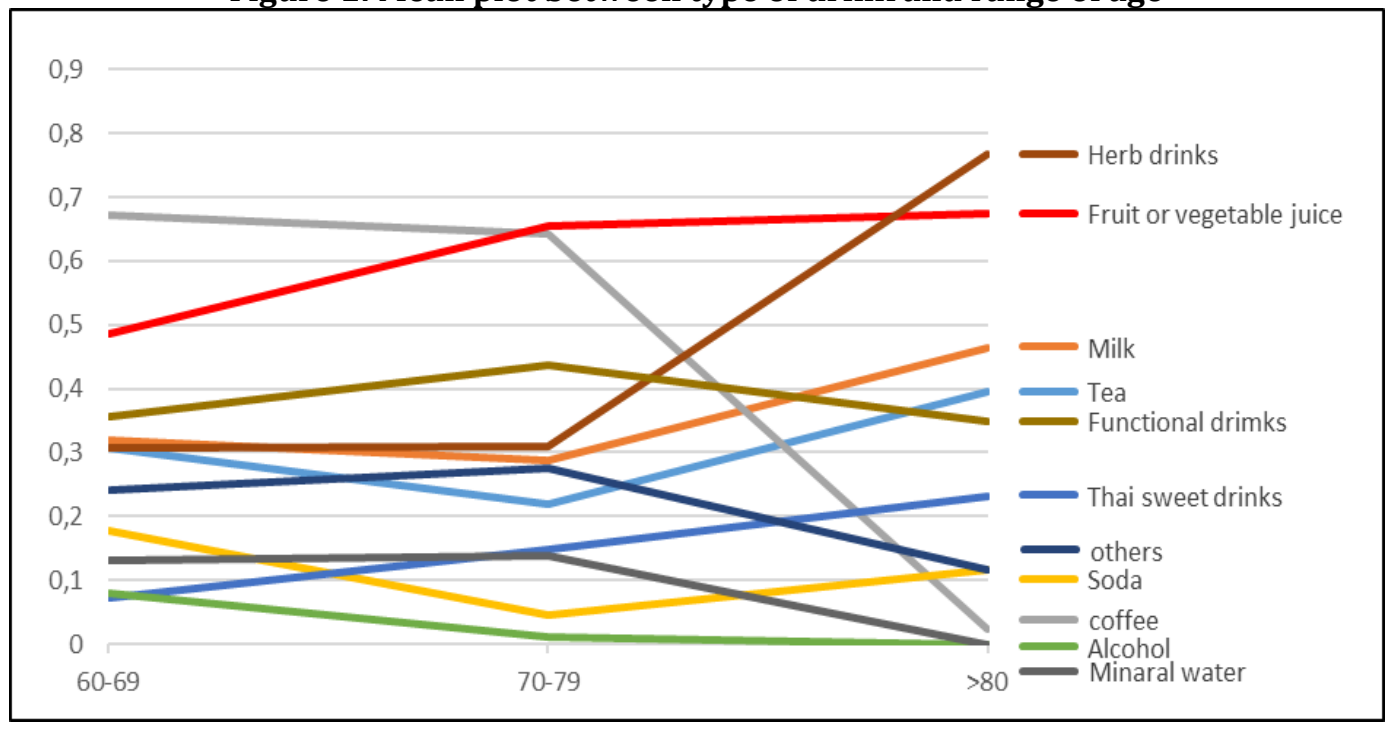


Figure 2: Forecast of Mean Plot between the type of drinks and the range of age (Only the increasing trend line)

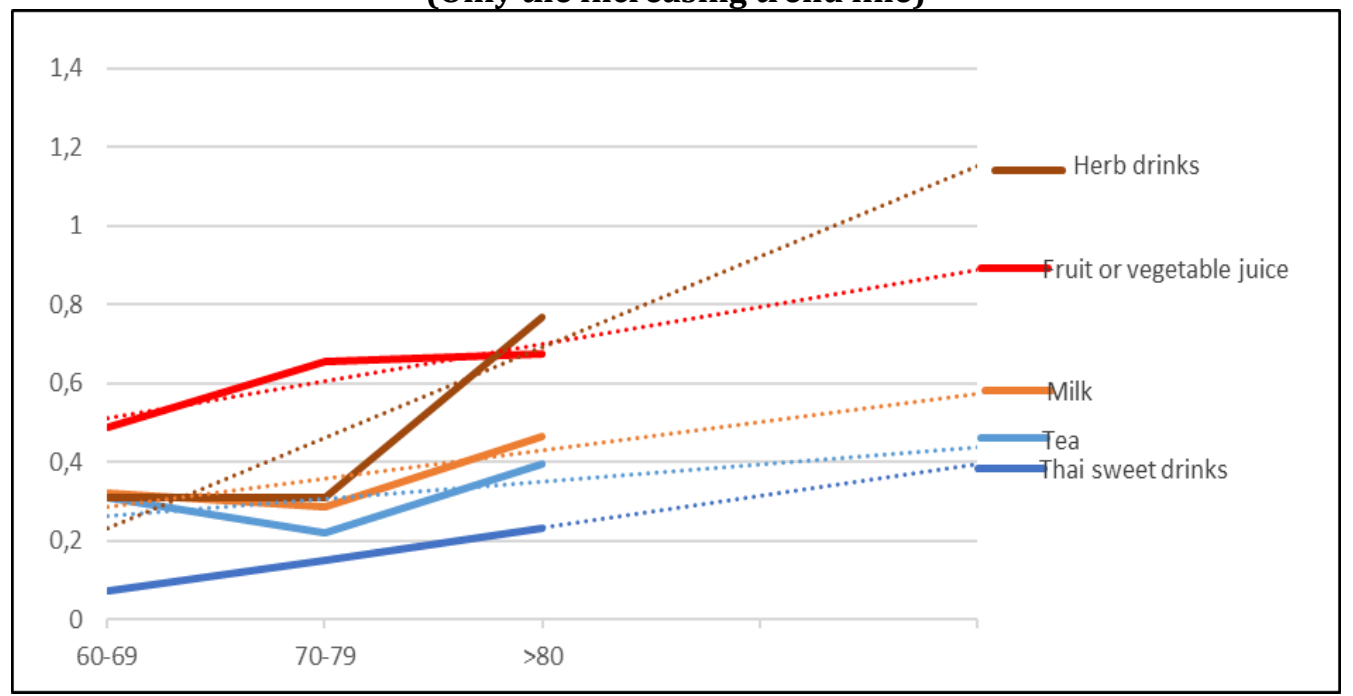

The results of the relation between demographics and factors are presented in Table 3 .

Test hypothesis 1: Demographic data and factors that affect healthy beverage consumption are different:

A comparison of the mean of gender and factors that affect healthy beverage consumption found to be equal, presents statistically significant evidence of 0.05 (Accept $\mathrm{H}_{0}$ ).

A comparison of the mean of age and factors that affect healthy beverages consumption are all equal, with statistically significant evidence of 0.05 (Accept $\mathrm{H}_{0}$ )

A comparison of the mean of education and factors that affect healthy beverages consumption are all equal, showing statistically significant evidence of 0.05 (Accept $\mathrm{H}_{0}$ )

A comparison of the mean of income and factors that affect healthy beverages consumption are all equal, with statistically significant evidence of 0.05 (Accept $\mathrm{H}_{0}$ )

A comparison of the mean of source of income and factors that affect healthy beverages consumption (ANOVA) are not equal, with statistically significant evidence of 0.05 (Reject $\mathrm{H}_{0}$ ). The source of income from pension has the highest average of factors that affect healthy beverage consumption of sons, daughters, working persons, those on savings, spouses, those on government living allowances and others.

\begin{tabular}{|c|c|c|c|c|c|}
\hline & Sum of Square & df & Mean square & $\mathbf{F}$ & Sig \\
\hline \multicolumn{6}{|l|}{ Gender } \\
\hline Between groups & 0.412 & 1 & 0.412 & 2.691 & 0.102 \\
\hline Within the group & 58.335 & 381 & 0.153 & & \\
\hline Total & 58.747 & 382 & & & \\
\hline \multicolumn{6}{|l|}{ Age } \\
\hline Between group & 0.146 & 2 & 0.730 & 0.473 & 0.624 \\
\hline Within group & 58.602 & 380 & 0.154 & & \\
\hline Total & 58.747 & 382 & & & \\
\hline \multicolumn{6}{|l|}{ Education } \\
\hline Between groups & 11.126 & 24 & 0.464 & 0.747 & 0.802 \\
\hline Within the group & 222.164 & 358 & 0.621 & & \\
\hline Total & 233.290 & 382 & & & \\
\hline \multicolumn{6}{|l|}{ Income } \\
\hline Between groups & 525.385 & 24 & 21.891 & 0.756 & 0.792 \\
\hline Within the group & 10369.711 & 358 & 28.966 & & \\
\hline Total & 10895.097 & 382 & & & \\
\hline \multicolumn{6}{|l|}{ Source of income } \\
\hline Between groups & 120.999 & 24 & 5.042 & 2.1230 & 0.002 \\
\hline Within the group & 850.249 & 358 & 2.375 & & \\
\hline Total & 971.248 & 382 & & & \\
\hline \multicolumn{6}{|l|}{ Living } \\
\hline Between groups & 45.509 & 24 & 1.896 & 2.586 & 0.000 \\
\hline Within the group & 262.517 & 358 & 0.733 & & \\
\hline Total & 308.026 & 382 & & & \\
\hline
\end{tabular}


A comparison of the mean of living situations and factors that affect healthy beverage consumption (ANOVA) are not equal, with statistically significant evidence of 0.05 (Reject $\mathrm{H}_{0}$ ). Living with only a spouse has the highest average of factors that affect healthy beverage consumption, followed by those living with child or grandchild, living with brothers/sister relatives, living with others and living alone.

Test hypothesis 2: Healthy drink consumption behavior is related to factors that affect healthy beverage consumption.

From the results, it is inferred that healthy drink consumption behavior based on the type of drink, glass per week, and average drink per day is not related to factors that affect healthy beverage consumption.

\section{In-depth interview}

Personal in-depth interviews based on the questionnaire by using results of the descriptive survey consider a sample of people aged between 60 and 69 years, with an undergraduate degree or its equivalent, now working with a benefit income more than 40,001 baht and living with only a spouse. This sample prefers to drink fruit or vegetable juice more than other beverages. The respondents were interviewed in a span of two weeks, from 30 April 2018 - 14 May 2018, with a total of six respondents (three men and three women).

From the in-depth interview, it is found that the elderly tend to be more cautious with the beverage consumed as they do not drink what they used to earlier. The elderly state that they prefer juices because they are delicious, easy to drink and have good benefits. Moreover, the present innovation and technology give them a variety of fruit juices to choose from based on health benefits and personal preferences.

Furthermore, people who influence the drinking behavior of the elderly are the ones they trust most. Even though in Thailand, the elderly nearly always lives with a child, the presence of a spouse affects them more than other family members because they have been together for a long time and of a similar age, leading to a level of trust. Experts follow, with their knowledge and experience to recommend good things to them.

\section{Conclusion}

The trends pointed out that aging people are quite concerned about health benefits. In other words, the demand for healthy beverage consumption increases with age. Fruit or vegetables juices are the best choice for them to maintain adequate intake of nutrients with changes in their psychological process and appetites. Another interesting trend is that of consumer behavior with respect to herbal drinks, which changes as people age.

Even though fruit or vegetable juice represent the market trend, in the future, herbal drinks may become equally or more popular than fruit or vegetable juices, due to the presence of diverse natural ingredients.

New beverages for aging consumers may combine fruit or vegetable juices and herbal drinks. For example, fruit peels can be used to make drinks. K. Masomrong and W. Suntornsuk's study (2014) reveals that dragon fruit peel extract is a source of antioxidants and natural antibacterial agents. As such, "dragon fruit peel drinks" are a potential product. In addition to the new product benefits that this introduces, it also helps reduce the amount of agricultural waste.

However, the dietary requirement of aging people is not solely based on age but also depends on individual, social, and environmental factors as stated by P. Kotler and K.L. Keller (2012) and Cabrini and Ajit (2006), who differentiate the elderly by cultural, social, and personal factors.

It is understood from the descriptive survey of the source of income and living situation, that they are important, given their direct effect on healthy beverage consumption. For example, aging people living with spouse always trust each other more than others. To attract a new segment of the aging population, persuasion through reliable and effective information dissemination is required.

Thus, this research shows that information on the types of drinks that aging people are interested in and accept are beneficial to entrepreneurs and consumers. It is particularly useful for product marketing and future product development, helping determine what product is comfortable and acceptable to them.

In addition, focusing on new product development and marketing for an aging society enables entrepreneurs to focus -on the income and benefits for this segment, presenting new challenges and opportunities in both the public and private sectors. This supports the demand of an increasing aging society. 


\section{Recommendations}

Aging consumers' dietary requirements are often complicated. It depends both on their preferences and health conditions. Therefore, it is difficult to focus on the overall elderly population, because their preferences vary based on habits, personal preferences, or other factors that could affect their behavior. If there is a need for a new product, producers should conduct direct research with in-depth targeting, instead of long-term data collection or daily research notes.

\section{Appendix A. Supplementary material}

Supplementary data associated with this article can be found, in the online version, at https://doi.org/10.14254/jems.2019.4-2.4

\section{Funding}

The authors received no direct funding for this research.

\section{Citation information}

Sapsanguanboon, W., \& Daoruang, R. (2019). Healthy beverage consumption among aging Thai consumers. Economics, Management and Sustainability, 4(2), 40-48. doi:10.14254/jems.2019.4-2.4.

\section{References}

Cronbach, L. J. (1951). Coefficient alpha and the internal structure of tests. Psychometrika, 16(3), 297-334.

de Morais, C., Afonso, C., \& De Almeida, M. D. V. (2010). Ageing and food consumption in Portugal: new or old paradigms?. British Food Journal, 112(5), 511-521.

Healthy beverage Market in Thailand: Thailand Food Market Report. (2016). National Food Institute, Retrieved January 10, 2018, from http://fic.nfi.or.th/MarketOverviewDomesticDetail.php?id=139

Hewlett, P., \& Wadsworth, E. (2012). Tea, coffee and associated lifestyle factors. British Food Journal, 114(3), 416-427.

Hongprasert, S, (2016). FIN talk: Food Innovation Trouble Shooting. Food and Beverage for the Elderly. In NAC2017 $13^{\text {th }}$ NSTD Annual Conference, pp. 6-16, Bangkok: NSTDA.

Masomrong, K., \& Suntornsuk, W. (2014). Antioxidant and antibacterial activities of natural extract from dragon fruit peel. The Journal of Agricultural Science, 45(2), 269-272.

Mrad, M. (2018). Brand addiction conceptual development. Qualitative Market Research: An International Journal, 21(1), 18-38.

Pak, C., \& Kambil, A. (2006). Over 50 and ready to shop: serving the aging consumer. Journal of Business Strategy, 27(6), 18-28.

Population projections for Thailand 2010-2040. (2013). Office of the National Economic and Social development board, Bangkok: Office of the National Economic and Social development board.

Roebuck, J. (1979). When does" old age begin?: The evolution of the English definition. Journal of Social History, 12(3), 416-428.

Rose, M. R. (2009). Adaptation, aging, and genomic information. Aging (Albany NY), 1(5), 444-450.

Roy, S., \& Sanyal, S. N. (2017). Perceived consumption vulnerability of elderly citizens: A qualitative exploration of the construct and its consequences. Qualitative Market Research: An International Journal, 20 (4), 469-485.

Ruenrom, G. (2016). Marketing Research (8th ed.), Bangkok: Chulalongkorn University Printing.

Thai Gerontology Research and Development Institute. (2016). Situation of the Thai Elderly 2015, Bangkok: The Foundation of Thai Gerontology Research and Development Institute (TGRI) and Institute for Population and Social Research, Mahidol University.

The 2014 Survey of the Older Person in Thailand. (2015). National Statistical Office, Bangkok: Text and Journal Publication Co., Ltd. 
United Nations. (2017). World Population Aging 2017, New York: United Nations.

Weinberger, M. (2001). UN, Personal correspondence, http://www.who.int/healthinfo/survey/agingdefnolder/en/

Yamane, T. (1973). Statistics: an introductory analysis. New York: Harper \& Row.

\section{Further reading}

Casini, L., Contini, C., Romano, C., \& Scozzafava, G. (2015). Trends in food consumptions: what is happening to generation X?. British Food Journal, 117(2), 705-718.

Caughey, P., Seaman, C. E. A., \& Parry, D. A. (1995). What do elderly people eat?. British Food Journal, 97(4), 12-29.

Vanhonacker, F., Lengard, V., Hersleth, M., \& Verbeke, W. (2010). Profiling European traditional food consumers. British food journal, 112(8), 871-886.

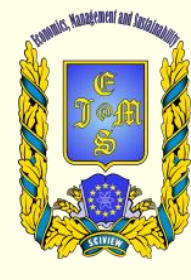

(c) 2016-2019, Economics, Management and Sustainability. All rights reserved.

This open access article is distributed under a Creative Commons Attribution (CC-BY) 4.0 license.

You are free to:

Share - copy and redistribute the material in any medium or format Adapt - remix, transform, and build upon the material for any purpose, even commercially.

The licensor cannot revoke these freedoms as long as you follow the license terms.

Under the following terms:

Attribution - You must give appropriate credit, provide a link to the license, and indicate if changes were made.

You may do so in any reasonable manner, but not in any way that suggests the licensor endorses you or your use.

No additional restrictions

You may not apply legal terms or technological measures that legally restrict others from doing anything the license permits.

Economics, Management and Sustainability (ISSN: 2520-6303) is published by Scientific Publishing House "CSR", Poland, EU and Scientific Publishing House "SciView", Poland

Publishing with JEMS ensures:

- Immediate, universal access to your article on publication

- High visibility and discoverability via the JEMS website

- Rapid publication

- Guaranteed legacy preservation of your article

- Discounts and waivers for authors in developing regions

Submit your manuscript to a JEMS at http://jems.sciview.net or submit.jems@sciview.net

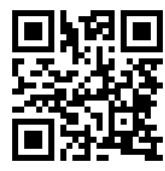

